\title{
ScienceDirect
}

Transportation Research Procedia 00 (2016) 000-000

Transportation

Research

Procedia

www.elsevier.com/locate/procedia

International Conference on Intelligent Transport Systems in Theory and Practice, mobil.TUM 2017, 4-5 July 2017, Munich, Germany

\section{Observations of trip generation, route choice, and trip chaining with private-sector probe vehicle GPS data ${ }^{*}$}

\author{
Christopher M. Day ${ }^{\dagger}$, Howell Li, Sarah M.L. Hubbard, and Darcy M. Bullock \\ Purdue University, West Lafayette, IN, 47906, USA
}

\begin{abstract}
This paper presents an exploratory study of GPS data from a private-sector data provider for analysis of trip generation, route choice, and trip chaining. The study focuses on travel to and from the Indianapolis International Airport. GPS data consisting of nearly 1 billion waypoints for 12 million trips collected over a 6-week period in the state of Indiana. Within this data, there were approximately 10,000 trip records indicating travel to facilities associated with the Indianapolis airport. The analysis is based the matching of waypoints to geographic areas that define the extents of roadways and various destinations. A regional analysis of trip ends finds that travel demand for passenger services at the airport extends across a region spanning about $950 \mathrm{~km}$. Local travel between land uses near the airport is examined by generation of an origin-destination matrix, and route choice between the airport and downtown Indianapolis is studied. Finally, the individual trips are scanned to identify trip chaining behavior. Several observations are made regarding these dynamics from the data. There is some sample bias (types of vehicles) and opportunities to further refine some of the land use definitions, but the study results suggest this type of data will provide a new frontier for characterizing travel demand patterns at a variety of scales.
\end{abstract}

(C) 2016 The Authors. Elsevier B.V. All rights reserved.

Peer-review under responsibility of the scientific committee of the International Conference on Intelligent Transport Systems in Theory and Practice.

* This document was submitted on March 31, 2017, for the 2017 mobil.TUM International Scientific Conference on Mobility and Transport held in Munich, Germany. The paper was presented on July, 5, 2017.

${ }^{\dagger}$ Corresponding author. Tel.: +1-765-494-9601. E-mail address: cmday@purdue.edu

2214-241X (C) 2016 The Authors. Elsevier B.V. All rights reserved.

Peer-review under responsibility of the scientific committee of the International Conference on Intelligent Transport Systems in Theory and Practice. 
Keywords: Probe data; GPS data; Automated vehicle location; route choice; trip generation; trip chaining

\section{Introduction}

As components of the classical four-step planning model, trip generation and route choice are two fundamental areas of transportation systems analysis, and a longstanding challenge for observational studies (Bovy, 2009). Trip generation studies typically look at similar existing facilities to estimate the potential impact of proposed new facilities. Those generated trips are then distributed to analysis zones on the basis of population or similar factors. The trips are then assigned to routes. Several models of route choice have been developed and are used to predict the effects of investments or policies on traffic conditions and route performance.

Route choice studies have traditionally been conducted by travel surveys. One example would be the Tokyo PersonTrip Survey that has been conducted since the 1970s (Ge \& Fukuda, 2016). GPS data has enabled the automatic collection of detailed travel data. Numerous route studies have been done using GPS devices carried by volunteers during day-to-day travel (Dhakar \& Srinivasan, 2014; Kim \& Mahmassani, 2015; Li et al., 2013; Zhu \& Levinson, 2015). Route choice studies have also been done using passive detection of vehicles and vehicle re-identification methods (Hainen et al., 2011) and data mining of automatic vehicle location (AVL) data sets, such as cell phone data (Herring, 2010; Lee et al., 2015) and special data collection efforts, as from the trucking industry (Kamali et al., 2016).

In the past decade, several private sector data providers have established a market for roadway performance data based on analysis of mobile device trajectories. These were used to find average speeds for predefined roadway segments, which have been used in numerous performance evaluations for urban areas in general (Schrank et al., 2015) and specific roadways at the network and segment levels (Remias et al., 2014). Recently, those companies have begun to explore market opportunities for the timestamped GPS coordinates that are the basis for those segment speeds. Recent research has examined the use of such data for travel time estimation (Patire et al., 2015); this paper explores potential applications in related areas of transportation systems analysis.

Airports have a large economic impact on broad geographic region. It is important for public and private sector entities to understand the markets they serve to guide future infrastructure investments. The complexity of airport travel demands makes it challenging to find a common data source for understanding those patterns. Past studies of ground access have typically been conducted by analysis of revealed preference through ridership numbers of transportation services, or stated preference via user surveys (Gosling, 2008). This paper selects the example of an airport with a relatively large regional impact as a case study for exploring how emerging data sets can analyze connectivity to such facilities.

Indianapolis International Airport (IND) is a public airport located seven miles from downtown Indianapolis. IND is among the top 50 airports in the US, with over 66,000 scheduled departures and 4,159,000 enplanements in 2016 (BTS, 2017), and the busiest airport in Indiana. Besides serving commercial passengers, the airport also has extensive cargo operations, repair and maintenance facilities, two fixed based operators (FBO) and general aviation. IND serves as FedEx's second largest cargo hub in the world.

Primary ground access to the airport is via I-70. Parking includes approximately 8,000 spaces in the Economy lot, 3500 spaces in the garage, 540 spaces in the park and walk, as well as valet parking (IIA, 2017). IND has a separate cell phone lot and rideshare services (e.g., Uber and Lyft). Landside access fees are a significant source of revenues, providing approximately $30 \%$, or $\$ 142 \mathrm{M}$ (Tuohy, 2015). Other revenues come from fees from airlines, passengers and vendors. The airport is also served by a bus line along Washington Street that connects to the downtown area.

\section{Data Characteristics}

GPS location data was obtained from a private sector data provider for a 6-week period between May 1, 2016, and June 12, 2016. This dataset comprised waypoints within Indiana over that time period, including 12.8 million vehicle probes having over 980 million waypoints. The data provider aggregated the GPS observations from a variety of users, including navigation devices, mobile phone applications, and fleet telematics. The data roughly corresponds to vehicles, but also includes some other modes, as will be discussed later. 
The data consists of vehicle records, containing a trip ID, timestamp, and a geographic point representing a latitude and longitude. The trips are further categorized by characteristics identified by the data provider, including the driving profile, weight class, and type of probe source. This paper uses the driving profile as a means of separating the data into various vehicle types. The three main types of driving profiles include:

- Consumer vehicles (3.7 million trips). These represent non-commercial vehicles.

- Field service (2.9 million trips). These represent a variety of commercial vehicles. Although labeled as "field service", the behavior of such vehicles moving between destinations strongly suggests that passenger services are well represented in this group.

- Private trucking (6.2 million trips). These represent freight vehicles.

Latitudes and longitudes are provided with four decimal places of accuracy. In Indiana (around roughly $40^{\circ} \mathrm{N}$ ), this provided a spatial resolution of $11.1 \mathrm{~m}$ in the east-west direction and $14.5 \mathrm{~m}$ in the north-south direction. This resolution is sufficient to associate vehicle positions with a roadway, but it is difficult to know, for example, the individual lane occupied by the vehicle. The time resolution of the data varied considerably. Some vehicles reported their position about once per second, whereas others reported a record once per 5 seconds, once per 10 seconds, with some reporting a location once per minute.

\section{Data Reduction}

To sort the waypoint data into travel patterns, the waypoints were referenced to maps. An initial dataset used for this purpose was a set of mileposts along state highways. Waypoints could be mapped to those mileposts by a shortestdistance method. However, local roads were not included. Another method of matching waypoints to roadway centerlines was attempted, but this frequently mismatched waypoints near intersections. Instead, the map was divided into geographic regions reflecting both roadways and land uses of interest. Waypoints were then matched to regions using a query function that determined whether the waypoint was within the area.

Fig. 1 shows the regions identified for characterizing travel between the Indianapolis airport and the downtown area. Areas are categorized as either "roadways", or "destinations", meaning adjacent land uses. For this study, the downtown area was considered to be a simple cordon area. Fig. 2 shows the land uses near the airport, which are divided into several categories. Details are provided for the IND passenger category, which indicates facilities dedicated to passenger service. To examine the distribution of demand throughout the region, a second map with larger regions was developed, covering Indiana and neighboring states. That map is presented in the next section.

The data was received as a list of waypoints, each associated with a particular Trip ID. Individual "trips" showed the travel record of a mobile device, but these did not necessarily correlate to an actual trip from one destination to another. Being the location record of a mobile device, this data would often include multiple "journeys" between several defined destinations. Trips were therefore broken into journeys on the basis of their departures and arrivals at destinations. The destinations shown in Fig. 1 and Fig. 2 were used to break "trips" into individual "journeys." All of the waypoints for a given trip were compared against the map (Fig. 1) to identify its location at each waypoint. If a destination was observed, the trip was considered to end at its arrival time (the first waypoint seen at the destination). The next journey would then begin at the last time observed at that destination.

Table 1 presents an example of a trip containing nine journeys for an individual trip over a 5-hour period. The departure and arrival times are respectively the last time observed at the start location, and the first time observed at the end location. The "next departure" time represents when the vehicle left the end location and began the next journey. The "dwell time" represents the time between the arrival and next departure time.

Eight of these trips were between locations identified in Fig. 1. The second trip represents travel to a location that is not defined on the map, followed by a later return to the same area near the airport. This was differentiated from a long dwell time at Short Term Parking, because the vehicle was observed on other roadways between observations at Short Term Parking (i.e., the vehicle was away from Short Term Parking between 6:47:04 and 7:26:10). This trip likely represents travel for a taxi or other such vehicle. 


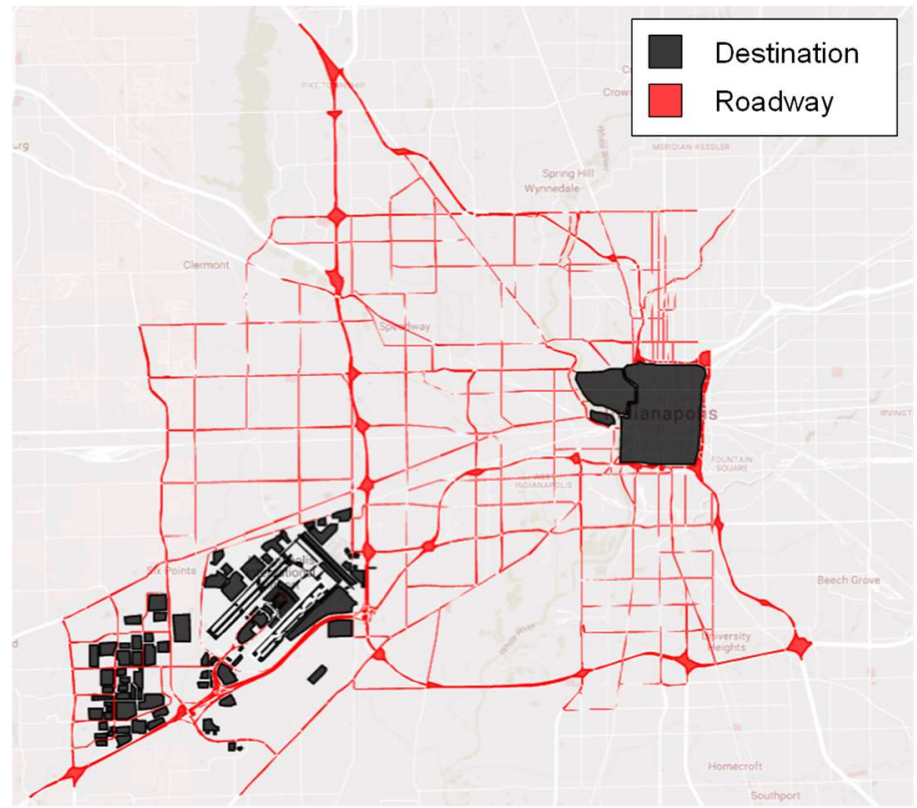

Fig. 1. Local geographic Areas for land use and route choice analysis.

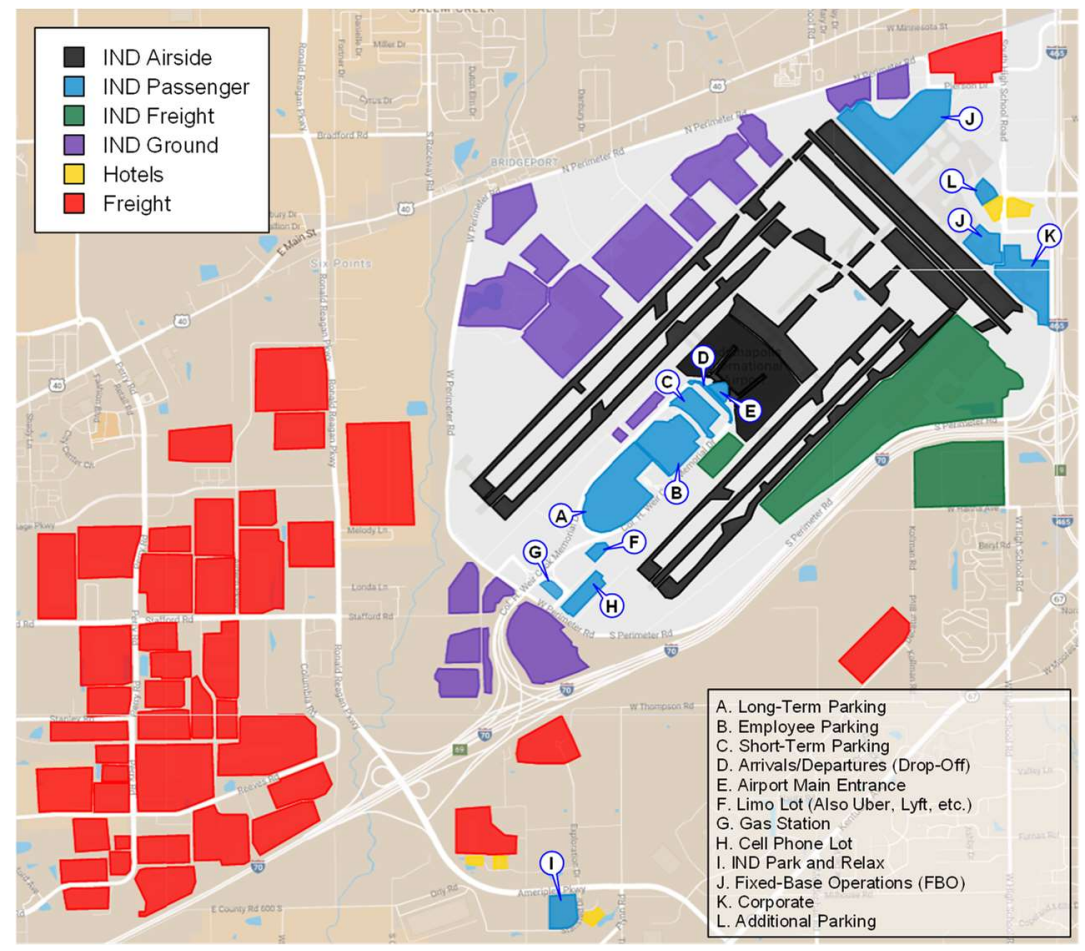

Fig. 2. Designation of local geographic areas (land uses) near the airport. 
Table 1. An example of a chained "trip" containing several "journeys".

\begin{tabular}{|c|c|c|c|c|c|c|c|}
\hline Journey & Start Location & End Location & Departure & Arrival & $\begin{array}{l}\text { Next } \\
\text { Departure }\end{array}$ & $\begin{array}{l}\text { Travel } \\
\text { Time } \\
\text { (min) }\end{array}$ & $\begin{array}{l}\text { Dwell } \\
\text { Time } \\
\text { (min) }\end{array}$ \\
\hline 1 & Limo Lot & Short Term Parking & $6: 37: 23$ & $6: 39: 23$ & $6: 47: 04$ & 2.0 & 7.7 \\
\hline 2 & Short Term Parking & Short Term Parking & $6: 47: 04$ & $7: 26: 10$ & $7: 33: 39$ & 39.1 & 7.5 \\
\hline 3 & Short Term Parking & Downtown & $7: 33: 39$ & $7: 46: 50$ & $7: 55: 53$ & 13.2 & 9.0 \\
\hline 4 & Downtown & Short Term Parking & $7: 55: 53$ & $8: 08: 39$ & $8: 11: 00$ & 12.8 & 2.4 \\
\hline 5 & Short Term Parking & Downtown & $8: 11: 00$ & $8: 25: 12$ & $8: 29: 06$ & 14.2 & 3.9 \\
\hline 6 & Downtown & Short Term Parking & $8: 29: 06$ & $8: 43: 25$ & $8: 45: 49$ & 14.3 & 2.4 \\
\hline 7 & Short Term Parking & Downtown & $8: 45: 49$ & $8: 58: 18$ & $9: 05: 56$ & 12.5 & 7.6 \\
\hline 8 & Downtown & Limo Lot & $9: 05: 56$ & $9: 16: 47$ & $9: 20: 32$ & 10.9 & 3.8 \\
\hline 9 & Limo Lot & Downtown & $9: 20: 32$ & $9: 37: 19$ & $10: 07: 13$ & 16.8 & 29.9 \\
\hline
\end{tabular}

\section{Analysis of Airport Trips}

\subsection{Regional Airport Passenger Service Trip Generation}

To understand the regional impact of the airport relative to passenger service, a second map was drawn over the extents of the waypoints associated with the airport. These were identified by isolating all the Trip IDs that had at least one waypoint within a geographic area in the "IND Passenger" category (Fig. 2). Fig. 3 shows a map of the trip waypoints and trip ends over a broad region including six states. These include both trips going to the airport and those coming from the airport. As the map shows, these trips extended as far east as Cleveland, $\mathrm{OH}$ and as far west as Columbia, MO, a range of about 600 miles $(950 \mathrm{~km})$. Fig. 3 also shows the location of other airports that would be potential alternatives, many of which are nearer to some trip endpoints. About 10,000 trip records with 2.7 million waypoints are included in this view.

The overall region was divided into areas. Table 2 shows a list of these areas, while Fig. 4 presents a map. These are ordered by the number of trip endpoints within each region. The map was drawn such that the further the distance from Indianapolis, which resides in Marion County (area 1), the larger the area would become. The map in Fig. 4 is colored according to the total number of trip ends observed in each region. Not surprisingly, the areas nearest to Indianapolis generate the largest number of trips, and overall most of the trips originate from within Indiana. However, there are quite a few trips that originate or terminate at a rather long distance from IND. For example, there are substantial number of trips originating from Illinois.

Some of the longer distance trips may represent the transport of rental cars from one airport to another. The rental car return area at IND is in the same area as short term parking (Fig. 2, callout $C$ ), so those trips would be captured when they report a waypoint in that area. On closer examination of the map in Fig. 3 it can be seen that some of the trip endpoints are indeed coincident with other airports, such as the trip ending at Memphis (MEM). However, many of the trip ends are not at one of these airports, showing that some demand is generated from a rather long distance from IND. In Table 2, the proportion of that demand is not insubstantial, with the broad region of Illinois outside of the Chicago and St. Louis areas having 72 trips compared to the 3625 from within the same county as the airport.

Table 2 shows the breakdown of trip endpoints by vehicle driving profile (as identified by the data provider), and between the FBO areas (Fig. 2) relative to all other parking facilities within the IND Passenger areas. For the most part, these results are unsurprising. Consumer vehicles account for the largest number of trips, while "Field Service" vehicles (which would include taxis) are about a third of that number. "Private trucking" (trucks) vehicles are rather few in comparison. There are a surprising number of trucks captured in the FBO areas, perhaps reflecting that FBO's often move high value, time critical items as well as passengers. 


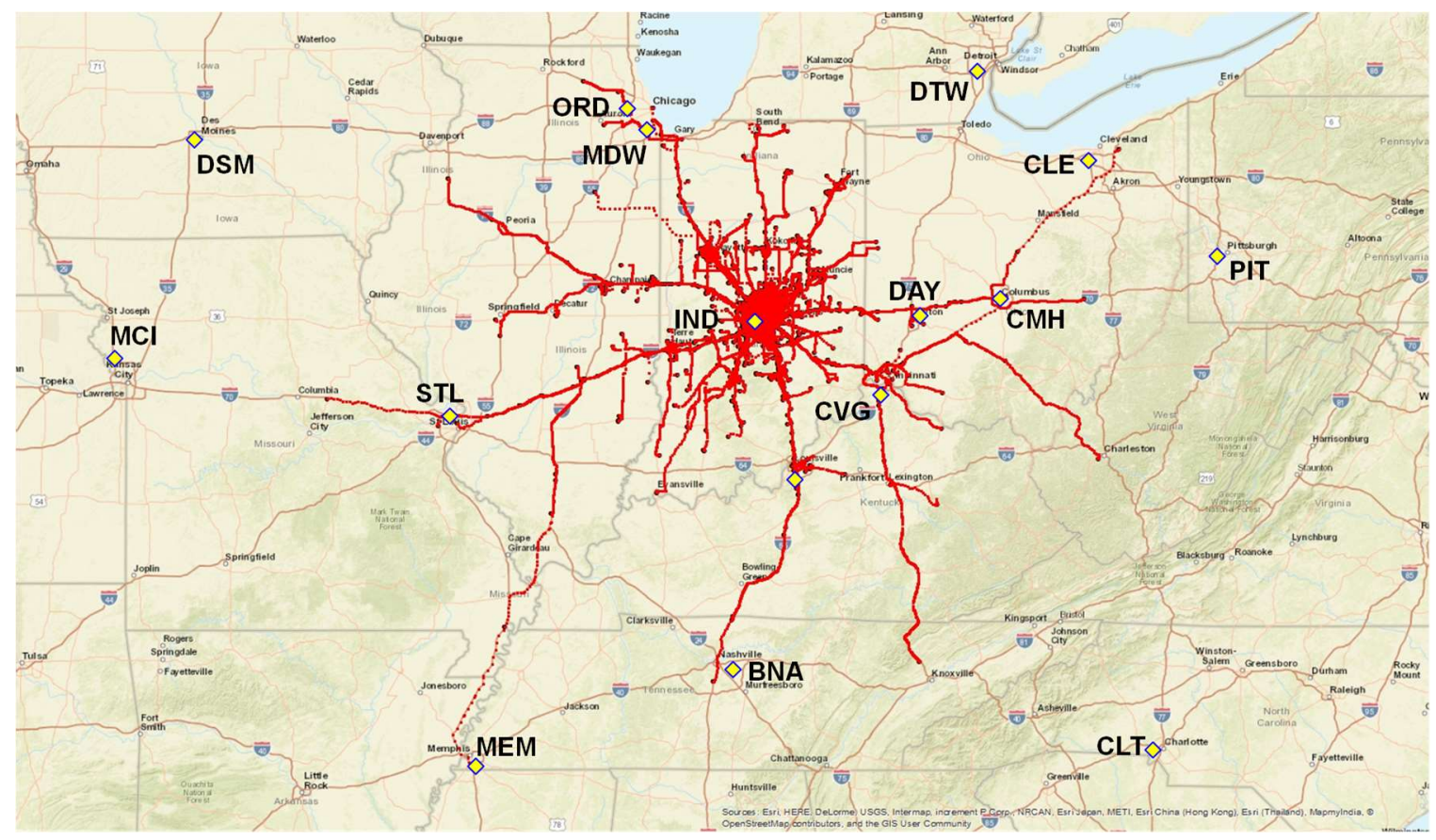

Fig. 3. Distribution of waypoints and trip ends from "IND Passenger" land uses.

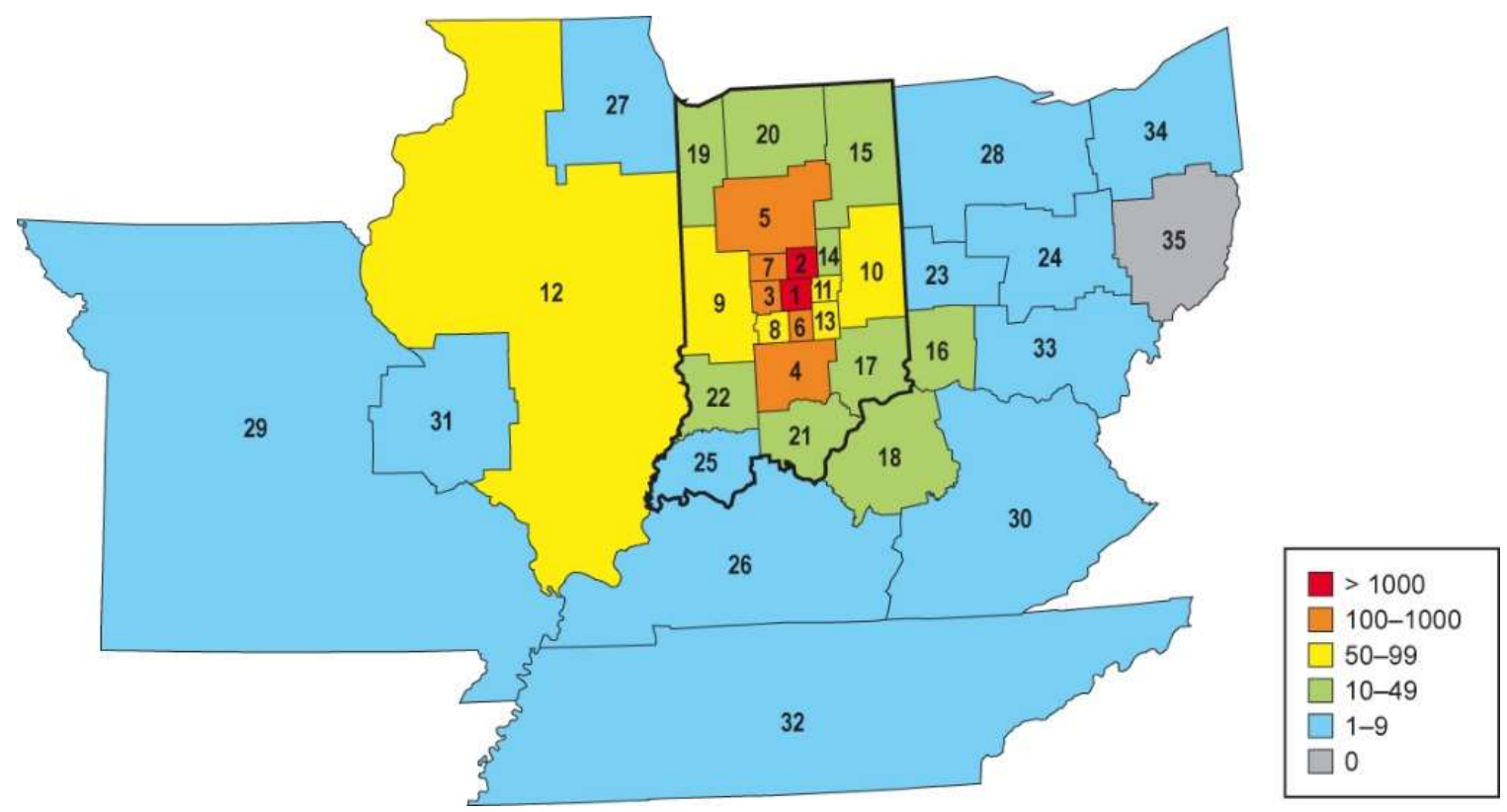

Fig. 4. Number of trip ends per region. 
Table 2. Distribution of trips endpoints by zone, categorized by vehicle driving profile and specific destinations.

\begin{tabular}{|c|c|c|c|c|c|c|c|c|}
\hline \multirow[b]{2}{*}{ No. } & \multirow[b]{2}{*}{ Area } & \multicolumn{2}{|c|}{ Consumer Vehicle } & \multicolumn{2}{|c|}{ Field Service } & \multicolumn{2}{|c|}{ Private Trucking } & \multirow[b]{2}{*}{ Total } \\
\hline & & Parking & FBO & Parking & FBO & Parking & FBO & \\
\hline 1 & Marion County & 2,414 & 119 & 892 & 108 & 13 & 79 & 3,625 \\
\hline 2 & Hamilton County & 1,379 & 15 & 225 & 7 & & & 1,626 \\
\hline 3 & Hendricks County & 305 & 14 & 118 & 9 & 9 & 41 & 496 \\
\hline 4 & South Central Indiana & 307 & & 57 & 2 & 1 & 1 & 368 \\
\hline 5 & North Central Indiana & 217 & 2 & 41 & 5 & & 2 & 267 \\
\hline 6 & Johnson County & 176 & 1 & 54 & 3 & 6 & 2 & 242 \\
\hline 7 & Boone County & 83 & 1 & 13 & 3 & & 1 & 101 \\
\hline 8 & Morgan County & 61 & & 34 & 2 & & 1 & 98 \\
\hline 9 & West Central Indiana & 66 & 2 & 10 & 2 & 1 & 3 & 84 \\
\hline 10 & East Central Indiana & 51 & & 22 & 2 & 3 & 5 & 83 \\
\hline 11 & Hancock County & 67 & & 13 & & & 2 & 82 \\
\hline 12 & Illinois & 49 & & 13 & & 3 & 7 & 72 \\
\hline 13 & Shelby County & 47 & & 10 & 1 & 3 & 4 & 65 \\
\hline 14 & Madison County & 24 & 1 & 12 & & 1 & & 38 \\
\hline 15 & Northeast Indiana & 28 & & 8 & 1 & & & 37 \\
\hline 16 & Cincinnati Area & 16 & 3 & 1 & & & 5 & 25 \\
\hline 17 & Southeast Indiana & 15 & & 5 & & 1 & 2 & 23 \\
\hline 18 & Louisville Area & 8 & & 2 & 2 & & 4 & 16 \\
\hline 19 & Northwest Indiana & 10 & & & 1 & & 1 & 12 \\
\hline 20 & Central Northern Indiana & 10 & & 1 & & & & 11 \\
\hline 21 & Central Southern Indiana & 6 & & 4 & & & 1 & 11 \\
\hline 22 & Vincennes Area & 8 & & 2 & & & & 10 \\
\hline 23 & Dayton Area & 8 & & & & & 1 & 9 \\
\hline 24 & Columbus Area & 2 & & & 2 & & 3 & 7 \\
\hline 25 & Evansville Area & 4 & & 1 & & & & 5 \\
\hline 26 & Western Kentucky & 3 & & & & & 1 & 4 \\
\hline 27 & Chicago Area & 3 & 1 & & & & & 4 \\
\hline 28 & Northern Ohio & 2 & & & & & & 2 \\
\hline 29 & Missouri & & & 1 & & & 1 & 2 \\
\hline 30 & Eastern Kentucky & & & 1 & & & 1 & 2 \\
\hline 31 & St Louis Area & 1 & & 1 & & & & 2 \\
\hline 32 & Tennessee & 1 & & & & & 1 & 2 \\
\hline 33 & Southern Ohio & & & & & & 2 & 2 \\
\hline 34 & Cleveland Area & 1 & & & & & & 1 \\
\hline \multirow[t]{2}{*}{35} & Southeast Ohio & & & & & & & 0 \\
\hline & Total & 5,233 & 155 & 1,483 & 148 & 41 & 171 & 7,231 \\
\hline
\end{tabular}




\subsection{Local Origin-Destination and Route Choice Observation}

Travel patterns near the airport were examined by looking at individual journeys passing between the different geographic areas defined in Fig. 2. It is possible to produce an origin-destination (O-D) matrix for all the individual "destination" areas, which would include 110 areas. To develop some insights, the areas are organized into seven groups as shown in Fig. 2. Table 3 shows three O-D matrices showing travel between these regions, for the three driving profiles identified by the data provider. Trips that return to the same initial location (such as the second journey in Table 1) are excluded. Of approximately 31,000 trips to and through destinations defined in Fig. 1, about 5,600 were associated with travel between these specific origin and destination areas, a significant amount considering that only a handful of possible destinations on the local map are defined.

Trips between different regions likely to reflect the magnitude of travel between them. The largest numbers are for consumer and field service vehicles between downtown Indianapolis and the IND Passenger areas. There are also relatively many truck trips between the Freight areas and the "IND Freight" areas within the airport (Fig. 2), which is not surprising. One unexpected result is the high number of truck trips between the IND Freight area and the Hotel areas, which may reflect some deliveries but may also be influenced by the proximity of some hotels to roadways serving the IND Freight areas. Higher fidelity GPS data could address that potential limitation.

Route choice was explored for travel between the IND Passenger areas at the airport and the cordon around downtown Indianapolis. Trips having one endpoint within one location and another endpoint at the other were isolated, and the waypoints along those particular journeys were matched to the roadways in Fig. 1. As Table 3, shows, the types of vehicles traveling between these regions is dominated by consumer and field service vehicles, with relatively few trucks.

Fig. 5 shows the distribution of those trips among the Indianapolis roadway network. By far, the most utilized roadway is I-70, which provides the most direct connection between the two areas. I-465 is the second most used route, with sections both north and south of the I-70/I-465 interchange having a relatively high number of trips. Many surface streets are also well represented. Among these, Sam Jones Expressway has the highest amount of traffic, which is unsurprising since that connects to facilities on the northeast side of the airport. Washington Street is the most direct surface street connecting downtown Indianapolis to the airport, but it is not particularly busy compared to the others. It was anticipated that some travel by the bus line on this route might be represented by somewhat heavy usage of Washington Street, but that did not appear to occur.

Of the 2,334 trips between downtown Indianapolis and the IND Passenger regions (Table 3), about $86 \%$ were found to have used I-70, 3\% used I-465, 1.5\% used Washington Street, 3\% used other surface streets, and the remainder, about $6.5 \%$ could not be identified because the intermediate waypoints were not matched to any roadway defined in Figure 1.

There is some impact of the heterogeneous time resolution of the data, as is evident in Fig. 5. That is, because some vehicles report their location at longer intervals, there is a tendency for shorter segments to be less represented in the data. For example, in Fig. 5, some of the shorter segments along I-70 have fewer vehicles identified as traveling along their length compared to two adjacent segments. It is unlikely that many vehicles left the roadway and returned; instead, the vehicles simply did not report a location while traveling along the shorter segment. 
Table 3. Origin-destination matrix for trips among different land-use areas.

\begin{tabular}{|c|c|c|c|c|c|c|c|c|}
\hline \multirow[b]{2}{*}{ Driving Profile } & \multirow[b]{2}{*}{ Origin } & \multicolumn{7}{|l|}{ Destination } \\
\hline & & Downtown & Freight & Hotel & IND Airside & IND Freight & IND Ground & IND Passenger \\
\hline \multirow{7}{*}{$\begin{array}{l}\text { a) Consumer } \\
\text { Vehicle }\end{array}$} & Downtown & & 52 & 25 & 3 & 29 & 20 & 629 \\
\hline & Freight & 60 & & 26 & 1 & 29 & 34 & 18 \\
\hline & Hotel & 34 & 20 & & 1 & 7 & 2 & 26 \\
\hline & IND Airside & 2 & 3 & & & 15 & 33 & 83 \\
\hline & IND Freight & 9 & 24 & 22 & 17 & & 22 & 60 \\
\hline & IND Ground & 14 & 26 & 5 & 13 & 25 & & 361 \\
\hline & IND Passenger & 668 & 13 & 41 & 69 & 47 & 405 & \\
\hline \multirow[t]{7}{*}{ b) Field Service } & Downtown & & 22 & 11 & & 6 & 11 & 506 \\
\hline & Freight & 16 & & 13 & & 1 & 2 & 10 \\
\hline & Hotel & 15 & 11 & & & & 3 & 6 \\
\hline & IND Airside & 2 & & & & 1 & & 5 \\
\hline & IND Freight & 3 & 3 & 4 & & & 3 & 17 \\
\hline & IND Ground & 5 & 2 & & 1 & 3 & & 12 \\
\hline & IND Passenger & 527 & 7 & 8 & 7 & 14 & 32 & \\
\hline \multirow{7}{*}{$\begin{array}{l}\text { c) Private } \\
\text { Trucking }\end{array}$} & Downtown & & 111 & 3 & & 6 & 107 & 2 \\
\hline & Freight & 49 & & 132 & & 145 & 11 & 5 \\
\hline & Hotel & 4 & 213 & & & 8 & 1 & \\
\hline & IND Airside & & & & & 4 & & \\
\hline & IND Freight & 3 & 209 & 111 & 2 & & 8 & 22 \\
\hline & IND Ground & 26 & 6 & 2 & & 29 & & 35 \\
\hline & IND Passenger & 2 & 7 & 5 & 1 & 23 & 4 & \\
\hline
\end{tabular}

\subsection{Trip Chaining}

As mentioned earlier, many of the trips in the dataset contain a number of trips between various locations. The example in Table 1 showed a vehicle that was likely a taxi, which had eight trips between destinations. Fig. 6 shows an analysis of the amount of trip chaining observed relative to airport or downtown Indianapolis locations (Fig. 1). This data was developed by considering the number of individual journeys between destinations associated with an individual trip ID, representing the same probe vehicle. "One sided" journeys include those that started or ended on a roadway. More than half the observed trips were one-sided, meaning that only one part of the journey was associated with a destination in Fig. 1. This is not surprising, since there are many other possible points where trips could begin in the region. Among defined destinations, most trips had one journey, and the number of trips with multiple stops drops off as the number of destinations increases. The maximum observed number of destinations was 29.

The amount of dwell time spent at a destination could be calculated by comparing the time of arrival with the time of the next departure, as shown by the example in Table 1. Fig. 7 shows the average dwell times at each of the individual defined destinations in Fig. 1. These are organized by land use category, and sorted from longest to shortest within each category. The average dwell times tend to be relatively short, lasting several minutes or less. There were a few dwell times lasting two hours or longer, with the longest dwell time being about 5 hours. 


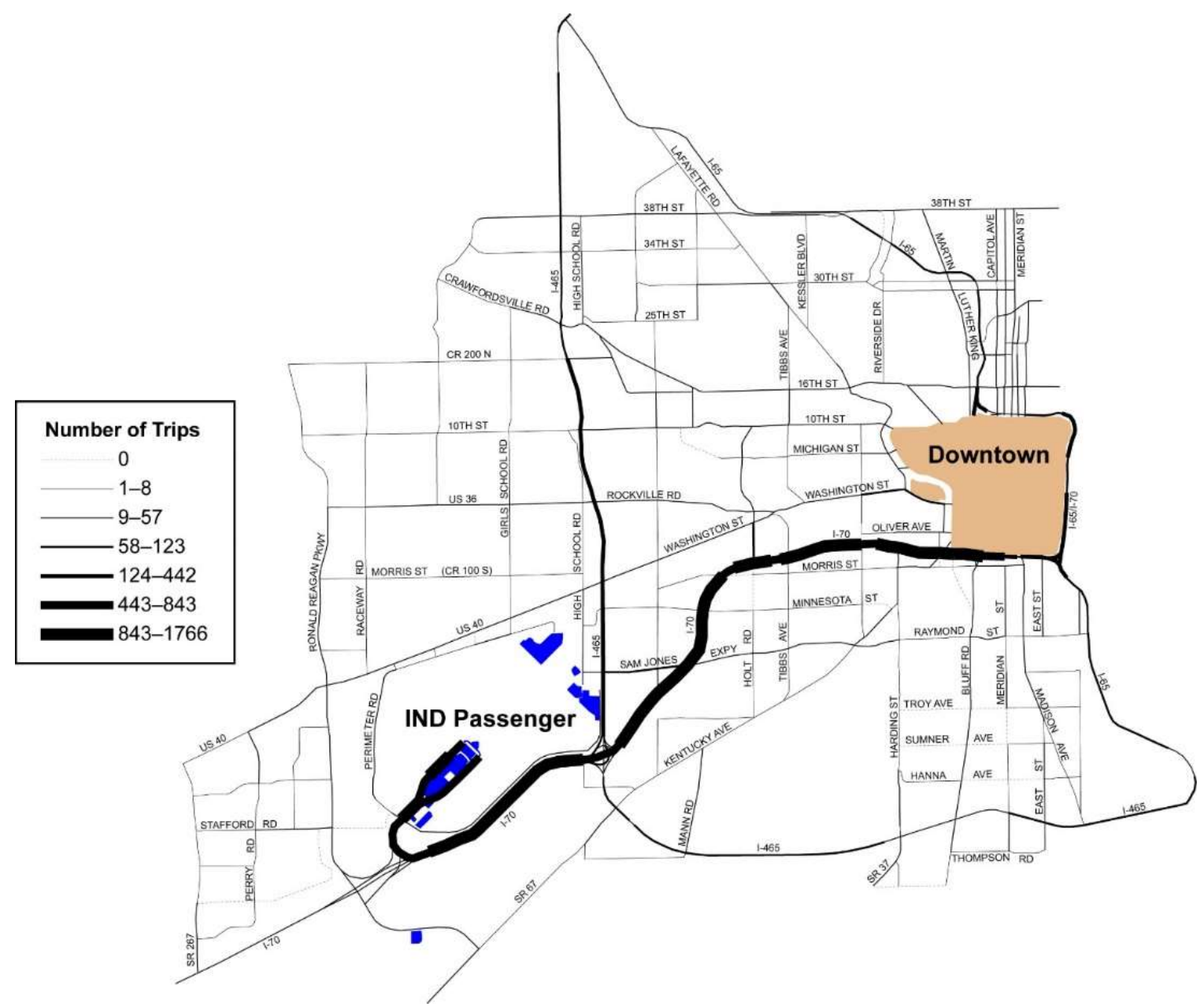

Fig. 5. Route choice between downtown Indianapolis and "IND Passenger" areas: Distribution of trips along Indianapolis area roadways.

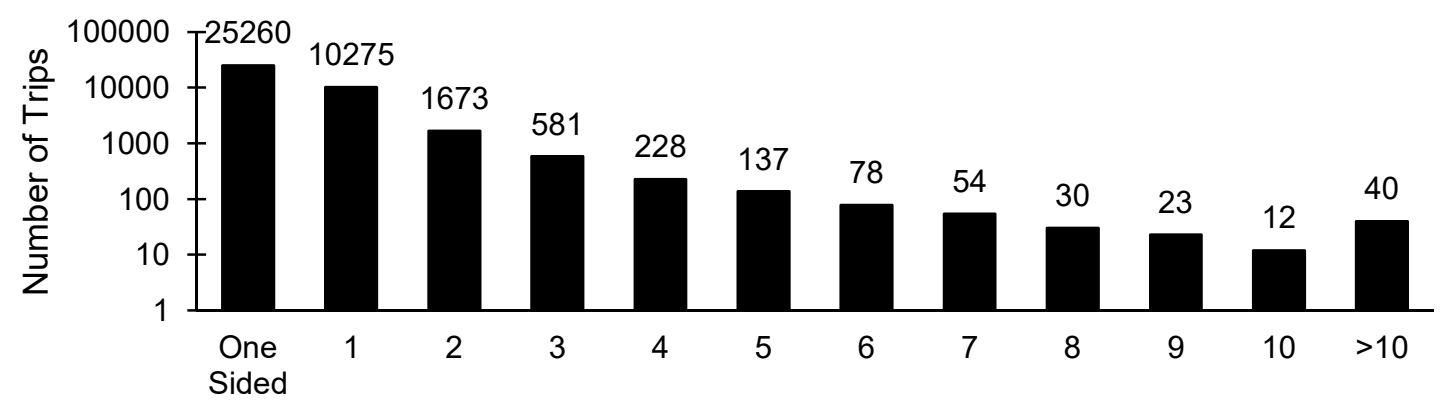

Number of Journeys Between Destinations

Fig. 6. Number of chained trips. 
Dwell times for "IND Airside" areas show times spent at various locations within the airport in which vehicles are less likely to be present, but some mobile devices are anticipated. It was hypothesized that some long dwell times might be observed for these areas, such as for a mobile app user waiting in a terminal for a flight, or perhaps associated with wait time at security checkpoints, as has been measured with Bluetooth MAC address matching (Remias et al., 2013). Nearly all of the vehicles having dwell times in the terminals were of the "Consumer Vehicle" driving profile. However, long dwell times were not observed; none of the "dwell times" in either terminal exceeded 12 minutes. An explanation for this is difficult to find when very long dwell times are seen in the downtown area, for example. It may be that some filtering is applied internally to avoid tracking stationary trips that are not close to roadways.

Fig. 8 shows a Pareto-sorted diagram of the individual dwell times of the top 500 dwell times per driving profile category. The chart shows that the "Private Trucking" category has shorter dwell times than the other categories. This is a somewhat unexpected result; many freight facilities were included in the map definitions (Fig. 2) and it was thought that some loading and unloading activity might be captured, which were expected to increase the dwell times for such vehicles. However, the data does not bear out such indications. Perhaps for trucks, the navigation devices reporting GPS waypoints might be unavailable during such activities, such as if the vehicle is shut off, and it when it begins reporting again, the new stream of waypoints may be established as a new trip by the data provider. Very heavy clustering of "private truck" trip start and endpoints near rest stops, freight stations, and similar facilities where trucks are likely to stop for long periods of time suggests that this is the case. The longer dwell times of consumer and field service vehicles, meanwhile, seem likely to correspond to mobile devices that are not powered down and continue to report GPS locations.

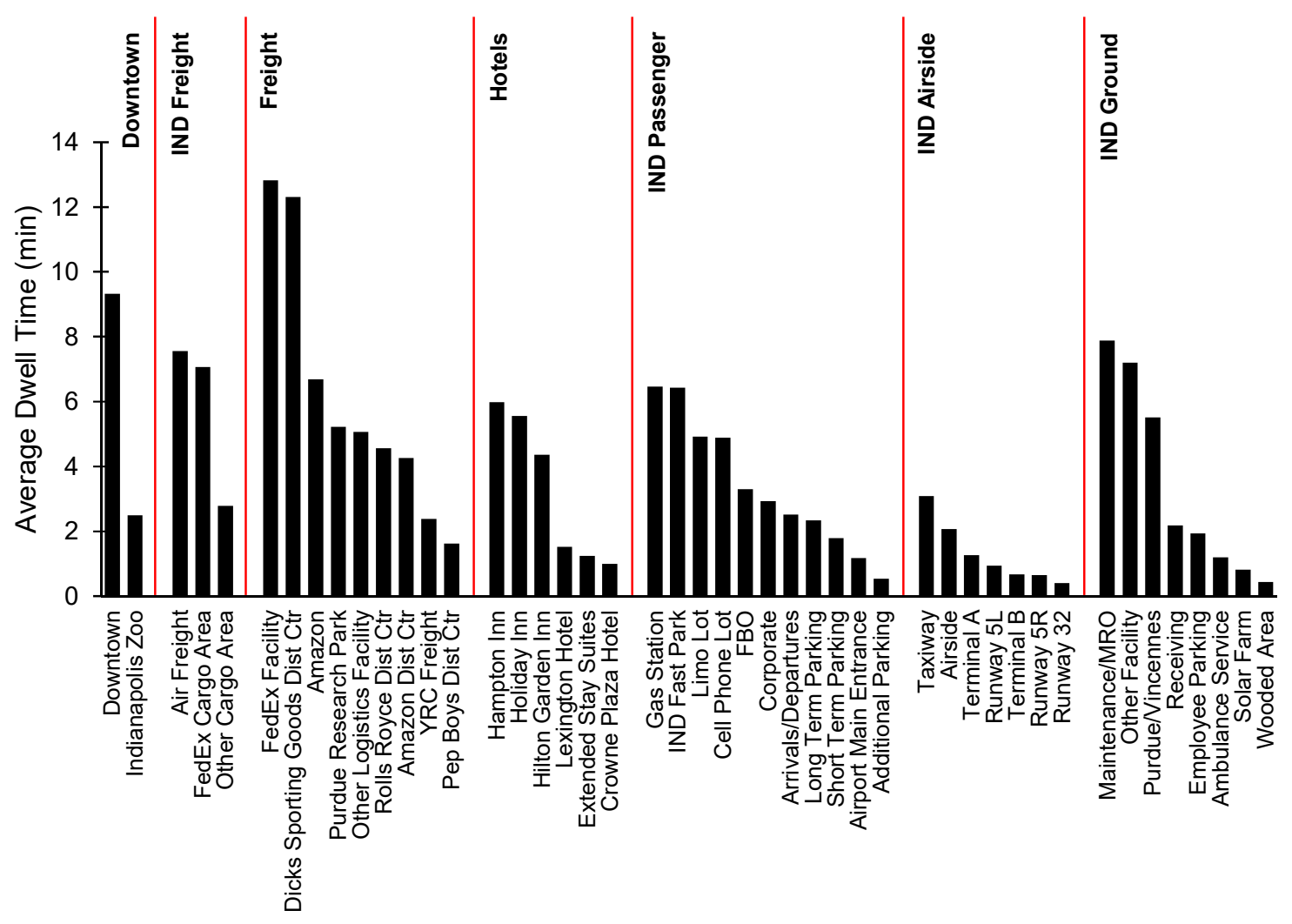

Fig. 7. Average dwell times for chained trips by location. 


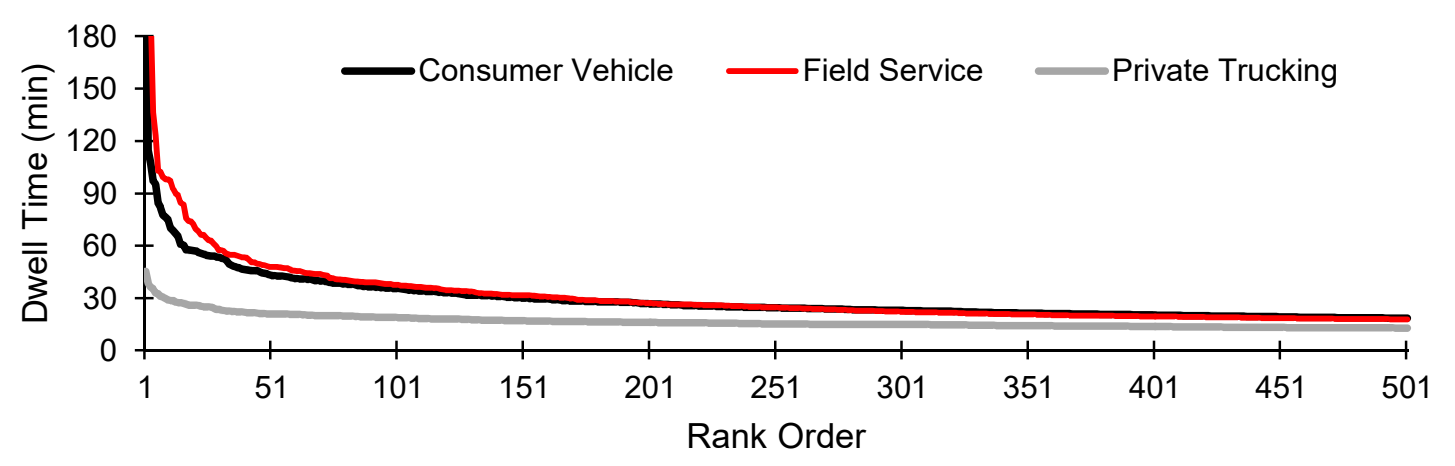

Fig. 8. Pareto-sorted dwell times categorized by driving profile.

\section{Conclusions}

This paper explored uses of private-sector probe vehicle GPS data to analyze trip generation, route choice, and trip chaining. A dataset was obtained from a vendor that included trips within or through Indiana during a 6-week period in May-June 2016. The entire dataset included nearly a billion waypoints from about 12 million trips. The data was matched to real-world locations on the basis of polygonal map areas on a local scale (Fig. 1, Fig. 2) and a regional scale (Fig. 4, Table 2).

An analysis of airport trip generation was conducted by examining the endpoints of trips made to airport destinations for passenger service. The distribution of those trips was found, as would be expected, to lessen with greater distance from the airport. Nevertheless, there were surprisingly many trips generated from regions served by other, nearer airports. Airports in particular often compete for market share, and Indianapolis in particular has sought to capture travelers from the overall region, particularly the Cincinnati market. Pervasive AVL datasets could augment other market research data used by entities such as airports to understand the landscape of their market area.

Local travel patterns were analyzed by comparing waypoints for trips between defined destination areas associated with the airport and downtown Indianapolis. An origin-destination matrix (Table 3) showing the numbers of observed trips, categorized by driving profiles. Driving profiles roughly correspond to categories of vehicles that represent noncommercial vehicles, and two classes of commercial vehicles (freight and non-freight). Route choice between pairs of destinations can also be identified. Travel between downtown Indianapolis and the airport was found to heavily favor the most direct route, I-70, but about $14 \%$ of trips used alternative routes.

Lastly, trip chaining was analyzed through examination of the distribution of the number of journeys between destinations for individual trips (Fig. 6) and the amount of dwell time spent at destinations (Fig. 6, Fig. 7). While some trip chaining could be observed, some limitations of the data with regard to chained trips were also observed. That is, there was a tendency for trips to be broken across stopping activities for certain activities (e.g., trucks; Fig. 7) or in certain areas (e.g., airport terminals; Fig. 7).

This paper provided an early look at potential uses of GPS data obtained from private-sector companies that aggregate it from multiple sources. These results demonstrate considerable promise for the data for such purposes, which parallel the insights that have been made from similar data sets obtained by other means. Future work would seek to refine these analysis methods further into tractable functions that can be fit into analytics dashboards for planners and engineers. Similar tools have been developed for travel times and incident detection (Li et al., 2015) which are now in common use by several agencies. The question of to what extent the data contains inherent bias is unanswered. The dataset shown in this paper has a stronger representation of commercial vehicles than noncommercial vehicles, for example; other datasets emerging from different sources will likely have some tendencies toward other demand segments. Likely, the fusion of multiple datasets would likely help provide some insights on how to adjust data to accommodate such factors. 


\section{Acknowledgements}

This study was supported in part by the Joint Transportation Research Program administered by the Indiana Department of Transportation and Purdue University. The data used in this study was provided by INRIX. The contents of this paper reflect the views of the authors, who are responsible for the facts and the accuracy of the data presented herein, and do not necessarily reflect the official views or policies of the sponsoring organizations. These contents do not constitute a standard, specification, or regulation.

\section{References}

Bovy, P.H.L. On modeling route choice sets in transportation networks: A synthesis. Transport Reviews, 29, 2009 , 43-68.

Bureau of Transportation Statistics. Indianapolis International Airport. Retrieved March 4, 2017 from https://www.transtats.bts.gov/airports.asp?pn=1\&Airport=IND

Dhakar, N.S. and S. Srinivasan. Route choice modeling using GPS-based travel surveys. Transportation Research Record No. $2413,2014,65-73$.

Ge, Q. and D. Fukuda. Updating origin-destination matrices with aggregated data of GPS traces. Transportation Research Part C, 69, 2016, 291312 .

Gosling, G. Airport Ground Access Mode Choice Models. ACRP Synthesis 5. Washington, D.C.: Transportation Research Board, 2008.

Hainen, A.M., J.S. Wasson, S.M.L. Hubbard, S.M. Remias, G.D. Farnsworth, and D.M. Bullock. "Estimating route choice and travel time reliability with field observations of Bluetooth probe vehicles." Transportation Research Record No. 2256, 2011, 43-50.

Herring, R.J. Real-Time Traffic Modeling and Estimation with Streaming Probe Data using Machine Learning. PhD Thesis, University of California Berkeley, 2010.

Indianapolis International Airport website. Retrieved March 4, 2017, from https:/www.indianapolisairport.com/

Kamali, M., A. Ermagun, K. Viswanathan, and A.R. Pinjari. Deriving truck route choice from large GPS data streams. Transportation Research Record No. 2563, 2016, 62-70.

Kim, J. and H.S. Mahmassani. Spatial and Temporal Characterization of Travel Patterns in a Traffic Network using Vehicle Trajectories. Transportation Research Part C, Vol. 59, 375-390, 2015.

Lee, D., K. Kung, and C. Ratti. Mapping the waste handling dynamics in Mumbai using mobile phone GPS. Proc., Computers in Urban Planning and Urban Management, 2015.

Li, H, S.M. Remias, C.M. Day, M.M. Mekker, J.R. Sturdevant, and D.M. Bullock. Shockwave boundary detection using cloud-based probe data. Transportation Research Board Annual Meeting, Paper No. 15-0714

Li, D., T. Miwa, and T. Morikawa. Use of private sector probe data in route choice analysis to explore heterogeneity in drivers' familiarity with origin-destination pairs. Transportation Research Record No. 2338, 2013, 20-28.

Patire, A.D., M. Wright, B. Prodhomme, and A.M. Bayen. How much GPS data do we need? Transportation Research Part C, $2015,325-342$.

Remias, S.M., A.M. Hainen, and D.M. Bullock. Leveraging probe data to assess security checkpoint wait times. Transportation Research Record No. 2325, 2013, 63-75.

Remias, S.M., T.M. Brennan, C.M. Day, H. Summers, D.K. Horton, E.D. Cox, and D.M. Bullock. Spatially referenced probe data performance measures for infrastructure investment decision makers. Transportation Research Record No. 2420, 2014, 33-44.

Schrank, D., B. Eisele, T. Lomax, and J. Bak. 2015 Urban Mobility Scorecard. College Station, TX: Texas Transportation Institute, 2015.

Tuohy, John. Cabs, Uber, BlueIndy, others help fill Indianapolis Airport's coffers. IndyStar, December 24, 2015. Retrieved March 4, 2017, from http://www.indystar.com/story/news/2015/12/24/cabs-uber-blueindy-others-help-fill-indianapolis-international-airports-coffers/75295514/

Zhu, S. and D. Levinson. "Do people use the shortest path? An empirical test of Wardrop's First Principle.” PLOS ONE, 10, 2015 , e0134322. 